\title{
UM ESTUDO SOBRE A CORRUPÇÃO E SUA INTERFACE COM O DIREITO
} AMBIENTAL

\author{
Valéria Giumelli Canestrini ${ }^{1}$ \\ Denise Schmitt Siqueira Garcia ${ }^{2}$
}

RESUMO: A pesquisa tem por objetivo analisar a prática de corrupção, conforme os pensamentos filosóficos, seu surgimento no Brasil e as consequências nos procedimentos de licenciamentos urbanos e ambientais. Justifica-se pela importância de se garantir os direitos sociais e uma qualidade de vida em um meio ambiente sadio, sem a interferência de interesses privados que corroem os sistemas em busca de mais lucro à custa de prejuízos sociais. Elegeu-se o método dedutivo, a técnica bibliográfica e a análise qualitativa. Ao final, pode-se compreender que a corrupção permeia os sistemas de licenciamentos urbano ambientais impedindo o exercício de direitos.

PALAVRAS-CHAVE: Corrupção; Direito; Licenciamento; Meio Ambiente; Urbanístico.

\section{A STUDY ON CORRUPTION AND ITS INTERFACE WITH ENVIRONMENTAL LAW}

ABSTRACT: The research aims to analyze the practice of corruption, according to philosophical thoughts, its emergence in Brazil and the consequences on urban and environmental licensing procedures. It is justified by the importance of guaranteeing social rights and a quality of life in a healthy environment, without the interference of private interests that erode systems in search of more profit at the expense of social losses. The deductive method, the bibliographic technique and the qualitative analysis were chosen. In the end, it can be understood that corruption permeates the urban environmental licensing systems, preventing the exercise of rights.

Key words: Corruption; Licensing; Environment; Right; Urbanistic.

\section{Introdução}

Uma visão panorâmica de práticas de corrupção, sua influência na cultura brasileira e sua interferência nas questões ambientais, é o que se encontrará na leitura do presente trabalho de pesquisa.

O artigo 225 da Constituição Federal de 1988, consagra um direito de terceira

\footnotetext{
${ }^{1}$ Mestranda em Direito pela Universidade do Vale do Itajaí (Univali). Especialista em Direito Civil e Processual Civil; em Direito Ambiental (UNIASSELVI). Promotora de Justiça no MPRO. E-mail: vcanestrini97@gmail.com

${ }^{2}$ Doutora pela Universidade de Alicante (Espanha). Mestre em Direito Ambiental pela Universidade de Alicante - Espanha. Mestre em Ciência Jurídica. Professora no Programa de Pós-Graduação, Stricto Sensu, da UNIVALI. E-mail: denisegarcia@univali.br.
} 
dimensão, que é o meio ambiente ecologicamente equilibrado e sadio à qualidade de vida (BRASIL, 1988). Na medida em que os atos de corrupção interferem nos procedimentos para licenças e construção de obras urbanas e ambientais, esse direito não se efetiva na sua plenitude, pois se não há garantias de um meio ambiente saudável, ocorrem interferências nos direitos à moradia, à saúde, a uma alimentação saudável, dentre outros; além de gerar inúmeros danos econômicos para a sociedade, enquanto poucos acabam se locupletando.

A problematização do artigo é justamente, verificar se a corrupção está presente nos processos envolvendo licenças ambientais e urbanísticas, objetivando-se apresentar várias posições de pensamentos e significados que a corrupção teve ao longo da história, como ela se enraizou na cultura brasileira e como ela interfere nos licenciamentos no meio urbano e ambiental.

A pesquisa é importante porquanto se debruça sobre um dos pontos mais problemáticos dos grupos sociais humanos, que é a corrupção. Além da degradação moral do homem, dos danos sociais provocados em função dela; cada vez mais, por meio de trocas de favores e por meio de pagamentos ilegais, não se respeitam as normas de proteção urbanística e ambiental.

O trabalho se estruturou da seguinte forma: No primeiro capítulo, são analisados, de forma inaugural, conceitos básicos que circundam o conceito de corrupção no decorrer da história da filosofia e outras correntes de pensamentos.

No segundo capítulo, a análise recai sobre o caráter de constatação e reconhecimento da corrupção na história do Brasil, desde seus primórdios até o período contemporâneo. Por fim, no terceiro capítulo, são delineados argumentos no sentido de confirmar a hipótese de que o a corrupção está presente nos procedimentos urbanísticos e ambientais para licenciamento e realização de empreendimentos, demandando a necessidade de tomada de providências e maior participação social para que essa prática seja evitada.

No que se refere aos aspectos metodológicos, foi eleito o método dedutivo, a utilização da técnica da Categoria, da técnica da Pesquisa Bibliográfica, para colher o material histórico-teórico necessário para a análise dos dados obtidos (PASOLD, 2011).

\section{Apontamentos gerais sobre o surgimento da corrupção}

A corrupção é fenômeno que acompanha a humanidade. Desde a Antiguidade, 
apontamentos existem de que mesmo na Bíblia, há indicativos da existência de práticas corruptas no meio social. O verbete "corrupção", numa definição simples, significa, de acordo com o dicionário Houaiss, de forma geral, a deterioração, a mudança da situação original, o corrompimento por agir em interesse próprio, prejudicando os demais (GRANDE DICIONÁRIO HOUAISS on line, 2021).

Derivado do latim, rumpere, um ato de corrupção, pode ser constatado de diversas maneiras, mas é sempre uma falta, uma quebra, um rompimento com normas já estabelecidas, com a prática de uma conduta visando um benefício próprio ou alheio e em prejuízo dos demais (TANZI, 1998).

Corrupção com origem na teologia, segundo Santo Agostinho, já no ano de 416, é ter o coração corrompido e pervertido; a própria essência do homem nesse sentido, seria ser desviada (BOFF, 2012).

De acordo com a filosofia clássica, na Grécia antiga, para Platão, após Heráclito, impulsionado pelas suas experiências pessoais da época, com as mudanças sociais, proclamou que toda mudança era uma forma de corrupção, de degeneração. Tudo o que foi gerado e criado seguiria um fluxo para a degradação, a decomposição que é para onde os homens são impulsionados (POPPER, 1994). Acreditava Platão, como exposto na sua obra o Estadista, que após a degradação total pela corrupção, poderia haver a reconstrução para um novo bem (PLATÃO A, on line).

A virtude era alcançada pelo crescimento intelectual e moral do homem, diferenciando-o dos demais seres vivos e cuidar da própria alma era cultivar a virtude (PLATÃO B. on line)

Aristóteles também se referia ao conceito de corrupção como a mudança de uma substância para sua caracterização oposta ou destruição (DICIONÁRIO DE FILOSOFIA, s. a.).

E ainda diferencia o homem justo do injusto, aquele propenso a infringir a lei (BARRETTO, 2009):

Diz Aristóteles que se o homem injusto é geralmente aquele que viola a lei e aquele que toma mais do que lhe é devido, faltando para com a igualdade, o homem justo será, ao revés, o que age conforme a lei e respeita a igualdade (passagem de uma disposição ao seu contrário tendo em vista o princípio segundo o qual 'frequentemente a disposição contrária é conhecida pelo seu contrário') (...) Dessa forma, pode-se dizer que o justo é aquele que é conforme a lei e respeita a igualdade, sendo o injusto aquilo que é contrário à lei e desrespeita a igualdade. 
Em pesquisa no dicionário de filosofia virtual, o verbete "corrupção":

Do latim corruptione. 1. Ação ou efeito de corromper; podridão, putrefação, decomposição. 2. Devassidão, depravação, perversão. 3. Modificação, mudança, alteração, adulteração. (1) Na ordem psicológica e moral, a corrupção denota um estado desordenado e patológico da consciência que leva o sujeito livre a exercer o mal ou pecado. Opõe-se à ordem da perfeição e da graça. $\mathrm{Na}$ ordem física, a corrupção é um fenômeno de involução dos entes materiais que possuem uma estrutura complexa e perfeita... Daí, o célebre adágio de Aristóteles e dos escolásticos: "A geração de uma coisa é a corrupção de outra".

Na Grécia antiga, havia mecanismos de combate a comportamentos de corrupção, e em Roma, Cícero era um dos ferrenhos combatentes do comportamento ímprobo nas funções públicas, com mecanismos de ações populares para o exercício da cidadania popular contra atos de prejuízo ao erário. No período medieval, a corrupção foi associada ao pecado e o homem era visto como um ser tendente a praticar atos de corrupção (CORDEIRO, 2017).

No período medieval, os pensadores entendiam a corrupção como um defeito no regime político:

\begin{abstract}
Na modernidade Ménissier (2007) destaca que, de um lado, pensadores políticos compreendiam a corrupção como uma forma de perversão ou patologia do regime governativo. Neste sentido, Maquiavel defende que a corrupção nada mais é do que "a exclusão do povo dos 'negócios de governo' que se faz através do controle político de um grupo oligarca" (MAQUIAVEL, 1994, p. 74). A corrupção surgiria, de acordo com o florentino, com a inaptidão para a vida em liberdade, que nasce, justamente, da desigualdade que foi inserida no seio do Estado. Observe-se que, neste momento, a corrupção era compreendida como um processo natural e atemporal, pelo qual deveriam passar todas as repúblicas, e o ciclo de decadência dos sistemas políticos só poderia ser retardado, o que ocorreria através de uma forma mista de governo republicano, misturando elementos monárquicos e aristocráticos, mas deixando prevalecer, ao final, o sistema republicano (CORDEIRO, 2017)
\end{abstract}

Maquiavel se ocupou de tratar da virtude exigida tanto do governante como do povo a fim de impedir que atos de corrupção fizessem a ruína do Estado. A corrupção seria o cenário de desigualdade que impediria o exercício livre do povo, podendo acontecer em ciclos a serem superados pela renovação política: “A corrupção e a inaptidão para a vida em liberdade provêm da desigualdade que se introduziu no Estado;" (MACHIAVELLI, 2017).

A corrupção até o período contemporâneo, sempre esteve relacionada a práticas políticas ou morais, baseadas no agir do indivíduo, resultando em atos corruptivos:

Pode-se concluir que poucas foram as flutuações semânticas da palavra ao longo dos séculos XVII e XVIII, prestando-se ela a designar os comportamentos morais ilícitos. Se a noção de corrupção, no sentido de desvio moral ou político, não era estranha ao imaginário político da Época Moderna, é de se notar, porém, uma diferença significativa entre os usos contemporâneos da palavra e os do passado. Ao 
contrário do que ocorre em nossos dias, a corrupção não designa as práticas, mas é, antes, o resultado de práticas que geram a putrefação do corpo da República; ou seja, as práticas não são em si corruptas: elas desencadeiam o processo de corrupção. Ou ainda, o indivíduo que pratica atos ilícitos não é propriamente corrupto, mas sim corruptor. É a partir do final do século XVIII que a palavra sofre um crescente deslizamento semântico, tornando-se, aos poucos, sinônimo de práticas corruptoras, como deixa ver o dicionário de Antônio de Moraes Silva (ROMEIRO, 2015).

E, na contemporaneidade, a corrupção está relacionada com um processo, um mecanismo do meio social, desvinculado de valores, em que há uma quebra de confiança entre os representados e seus representantes. O grau de confiança irá variar de acordo com resultados, confiança tanto na atividade de indivíduos como voltada ao funcionamento dos sistemas. Para as pessoas confiarem em agentes públicos, a atribuição da probidade, da honra, é relevante.

Tanto mais expostas situações que envolvam corrupção, má-fé, falta se eficiência nos serviços públicos, menos credibilidade nos agentes políticos. Na obra de Gidens, podemos identificar perfeitamente essa questão:

\begin{abstract}
A confiança está basicamente vinculada, não ao risco, mas à contingência. A confiança sempre leva à conotação de credibilidade em face de resultados contingentes, digam estes respeitos a ações de indivíduos ou à operação de sistemas. No caso de confiança em agentes humanos, a suposição de credibilidade envolve a atribuição de "probidade" (honra) ou amor. É por isto que a confiança em pessoas é psicologicamente consequente para o indivíduo que confia: é dado um refém moral à fortuna. Neste ponto chegamos a uma definição de confiança. A confiança pode ser definida como crença na credibilidade de uma pessoa ou sistema, tendo em vista um dado conjunto de resultados ou eventos, em que essa crença expressa uma fé na probidade ou amor de um outro, ou na correção de princípios abstratos (conhecimento técnico). (GIDDENS , 1991)
\end{abstract}

A corrupção por fim, amolda-se à realidade histórica e cultural de cada população, em que vários fatores são considerados, como a idoneidade dos chefes políticos, como o nível de participação popular, e com esses fatores é possível se analisar onde o Brasil se mostra nesse cenário (CORDEIRO, 2017).

\title{
3 A corrupção no contexto brasileiro
}

A corrupção além de ser uma falha no sistema representativo, uma distorção do sistema democrático com consequente prejuízo ao erário, é um desrespeito ao bem público, aos princípios republicanos, com total quebra de confiança no sistema político (FILGUEIRAS, 2011). 
A função sistêmica da corrupção que tem se mantido em sua maioria atualmente, é com base na análise econômica, o agente burla todas as regras, as normas previstas a fim de atingir o maior lucro. Nesse sentido:

\begin{abstract}
Em resumo, trata-se de uma forma de análise que parte de pressupostos majoritariamente econômicos. Busca-se compreender uma série de configurações institucionais que permitem a "maximização dos lucros" dos agentes públicos e de mercado que buscam o enriquecimento em detrimento das normas coletivas de proteção ao patrimônio e à moralidade pública.( CORDEIRO, 2017)
\end{abstract}

Analisando-se a história do Brasil, constata-se que a corrupção, acompanhou todo o contexto histórico brasileiro, desde a chegada da família real. Somente a partir da Constituição Federal de 1988, é que houve uma preocupação maior com os princípios da transparência e moralidade (NASCIMENTO, 2016).

A vertente do patrimonialismo está impregnada na história administrativa do Brasil, prática decorrente dos países ibéricos, como Portugal, em que não havia separação entre o que é público ou privado, podendo assim, os funcionários públicos utilizarem-se desses meios para desfrutarem privilégios e posições políticas. Quem exercia os altos cargos no Estado, tinha total poder e controle do sistema produtivo e mercantil, favorecendo o aparecimento da corrupção.

E foi o que se formou no Brasil, um Estado centralizador, explorador de riquezas com distribuição de privilégios a quem se encontrava no poder, com senso de pessoalidade, de indolência e de falta de compromisso com o sistema público, prevalecendo a informalidade. ${ }^{3}$

Já no Brasil colônia, foram identificadas práticas de corrupção por servidores públicos para facilitar a soltura de condenados, como na prolação de sentenças e nas ações de não tributação. Em 1808, quando Dom João, príncipe regente de Portugal, veio para o Brasil, fugindo do ataque de Napoleão, seguiram-se as trocas de favores e concessão de privilégios, já que teve que se acomodar em casa de traficante de escravos, misturando-se o público e o privado (DALLAGNOL, 2017).

\footnotetext{
3 “O resultado do patrimonialismo é que a corrupção faz parte de um cotidiano de nossa constituição histórica. O clientelismo, a patronagem, o patriarcalismo e o nepotismo constituem tipos de relação do Estado com a sociedade em que a corrupção é a marca fundamental; afinal, à sociedade nada resta senão buscar o acesso aos privilégios do estamento burocrático mediante a compra de cargos públicos e títulos de honraria, favores da burocracia e a participação no erário do Estado." In: FILGUEIRAS, Fernando. A tolerância à corrupção no Brasil: uma antinomia entre normas morais e prática social. Opin. Publica, Campinas, v. 15, n. 2, p. 386-421, Nov. 2009. Disponível em: <http://www.scielo.br/scielo.php?script=sci_arttext\& pid=S010462762009000200005\&lng=en\&nrm=iso>. Acesso em: 05 set. 2020.
} 
O historiador Laurentino Gomes relata que entre 1816 a 1822 vários fatos de corrupção foram identificados, utilizando-se o dinheiro público para a manutenção de privilégios dos detentores do poder:

\begin{abstract}
Outra herança da época de dom João é a prática da 'caixinha' nas concorrências e nos pagamentos dos serviços públicos. O historiador Oliveira Lima, citando relatos do inglês Luccock, diz que se cobrava uma comissão de $17 \%$ sobre todos os pagamentos ou saques no Tesouro público. Era uma forma de extorsão velada: se o interessado não comparecesse com os $17 \%$, os processos simplesmente paravam de andar. 'A época de dom João VI estava destinada a ser na história brasileira, pelo que diz respeito à administração, uma era de muita corrupção e peculato', avaliou Oliveira Lima. (GOMES, 2014)
\end{abstract}

E no transcorrer da história, seguiram-se episódios na década de 1950, na era Vargas, em que se firmou a expressão "mar de lama". Após, na década de 60, a expressão "rouba, mas faz", além de diversos casos reconhecidos na década de 90, prosseguindo-se com diversos casos amplamente divulgados na imprensa chegando-se aos gigantescos desvios da Petrobrás. No ranking da transparência internacional, em 2017, o Brasil estava em $79^{\circ}$ lugar, como mais ético, dentre 176 (em 2019, de 180 lugares, estava na posição 106 ${ }^{\mathrm{a}}$ ) (TRANSPARENCIA INTERNACIONAL on line, 2020), no entanto, no relatório do Fórum Econômico Mundial ficou em $4^{\circ}$ lugar como o país mais corrupto do mundo, considerando-se 138 países (DALLAGNOL, 2017).

$\mathrm{Na}$ análise do contexto da corrupção no Brasil, é interessante a ponderação de que valores morais universais, embora entendidos, não são considerados ao serem toleradas práticas de corrupção para satisfação de necessidades sociais e econômicas do indivíduo. Como foi comprovado na pesquisa realizada pelo Centro de Referência do Interesse Público (CRIP) da Universidade Federal de Minas Gerais (UFMG) aplicado à amostra nacional entre 10 e 16 de maio de 2008, pelo instituto Vox Populi pelas regiões do território brasileiro e aplicada a um universo de 2421 pessoas maiores de 16 anos. $^{4}$

\footnotetext{
4 "O que os dados da Tabela 7 revelam, em contraposição à Tabela 6, é uma antinomia, existente no Brasil, entre normas morais e prática social. Ou seja, a corrupção não pode ser explicada pelo caráter do brasileiro, por sua cordialidade, malandragem ou esperteza, porque ele é capaz de absorver conteúdos substantivos da moralidade política, ao discordar de situações de corrupção. Os entrevistados consideram errado um político receber dinheiro para favorecer uma empresa em uma licitação, ou um empresário financiar campanhas esperando receber algo em troca. Porém, quando é para proteger a família, um pouco de corrupção é tolerável ou, se houver necessidade, é correto vender o próprio voto. Nesse caso, os entrevistados têm noção dos valores públicos, mas os juízos de necessidade corrompem, frente a uma tolerância da corrupção vista no outro, nunca em si mesmo. Existe uma disposição prática do brasileiro a entrar em esquemas de corrupção, que contrasta com sua configuração moral.”.” In: FILGUEIRAS, Fernando. A tolerância à corrupção no Brasil: uma antinomia entre normas morais e prática social. Opin. Publica, Campinas, v. 15, n. 2, p. 386-421, nov. 2009. Disponível em:
} 
Do que se comprova a assertiva de que grande parte das pessoas não estão disposta à moralidade, ou seja, de efetivarem todas as medidas possíveis para obter e expressar uma conduta moral.

O homem deve ter todo o cuidado consigo mesmo em respeito à própria faculdade superior de que é dotado, ou seja, cada um, sendo soberano de si mesmo, deve exercitar tal soberania ao invés de delegá-la às paixões, sendo a obediência à moralidade obrigação irrenunciável formulada sob a forma do imperativo categórico.( SANTOS, 2011)

Dessa exposição da realidade brasileira constata-se que há demanda da necessidade de aprimoramento dos institutos de democracia, participação popular e internalização de todos os elementos conceituais do que é bem público.

\section{A corrupção na área urbano-ambiental}

Da corrupção decorrem custos altos que prejudicam nos direitos da sociedade. Da corrupção decorrem mortes por falta de remédios e médicos na área da saúde, fome por falta de merenda escolar, prejuízo no direito à educação pelo desvio de verbas dessa área e da mesma forma na questão urbana-ambiental: as pessoas sofrem com danos produzidos por empresas que conseguem licenças por meios corruptos a fim de obterem mais lucros com poluição, falta de estrutura da cidade, com a degradação ambiental. A corrupção aumenta o custo dos empreendimentos, favorece o desvio de recursos públicos para alocação em projetos desnecessários, exclui as pessoas pobres e grupos minoritários de serviços públicos essenciais, contribuindo para a perpetuação da pobreza, destrói a confiança e a lisura das relações públicas (ORGANIZATION FOR ECONOMIC CO-OPERATION AND DEVELOPMENT, 2014).

Com o passar da história, o homem passou da fase de coletor caçador, da fase agrícola, para viver em assentamentos urbanos, o homem urbano, e estes assentamentos, cada vez mais lotados de pessoas em moradias inadequadas, vivendo em meios de desequilíbrio ambiental, sem uma sadia qualidade de vida. Ao tratar do homem empático, em uma civilização empática, Rifkins, (p. 416) nos apresenta a seguinte constatação:

<http://www.scielo.br/scielo.php?script=sci_arttext\&pid=S0104-62762009000200005\&lng=en\& Acesso em: 05 set. 2020.

nrm=iso>. 
Las consecuencias entrópicas de la urbanización son espantosas. Naciones Unidas estima que de los 3.500 millones de personas residentes en áreas urbanas, una de cada tres vive en barriadas pobres, asediada por la contaminación del aire, la contaminación del agua potable y las aguas residuales sin canalizar. Muchos habitan terrenos contaminados o cerca de vertederos. Los barrios de chabolas son los fregaderos de la energía no utilizada de nuestras ciudades, lugares donde se acumula la corriente de residuos producida por el flujo energético. El impacto sobre la salud es asombroso. La malaria, las enfermedades diarreicas, la bronquitis, la neumonía y otras enfermedades respiratorias, así como la exposición a residuos químicos y tóxicos, matan a millones de habitantes de los barrios de chabolas de las ciudades cada año."

E nesse contexto, sobressai a corrupção empresarial praticada junto com o poder público com o objetivo da garantia da sobreposição de interesses privados, sem qualquer preocupação com a população ou meio ambiente.

Assim, a corrupção urbano-ambiental é devastadora, na medida em que retira de toda a coletividade a garantia de ter um meio ambiente natural e artificial saudável, inserindo-se a real proteção dos direitos sociais, como o direito de moradia, o direito às justas condições de trabalho, direito à saúde.

Embora existam várias regulações de procedimentos para a instalação de empreendimentos urbanos e ambientais, o que se identifica são associações criminosas que interferem no parcelamento urbano, na regularização fundiária, na prestação da coleta e destinação de resíduos sólidos, no oferecimento de equipamentos urbanos, inclusive de lazer, com obtenção de licenças e autorização ao arrepio de danos ambientais, falta de estudos de impacto de vizinhança, de relatórios ambientais (CADORE, 2020).

Para essa corrupção ter seu lugar nas cidades, corrompendo os processos de licenças (PRESTES, 2018), lista uma série de fatores, como a desregulamentação, na falta de normas claras; a discricionariedade que favorece a flexibilização dos procedimentos pelos agentes públicos; a demora no processo administrativo (“dificuldades são o meio pelo qual podem ser vendidas facilidades"); excesso de departamentos sem finalidades atualizadas; o excesso de normas a serem satisfeitas.

E avaliando-se a Agenda 2030 (NAÇÕES UNIDAS BRASIL), vários de seus

\footnotetext{
5 “As consequências entrópicas da urbanização são terríveis. As Nações Unidas estimam que dos 3,5 bilhões de pessoas que vivem em áreas urbanas, uma em cada três vive em favelas, assoladas pela poluição do ar, contaminação da água potável e esgoto não canalizado. Muitos vivem em terrenos contaminados ou perto de aterros. As favelas são os sumidouros de energia não utilizada em nossas cidades, locais onde o fluxo de resíduos produzidos pelo fluxo de energia se acumula. O impacto na saúde é impressionante. Malária, doenças diarreicas, bronquite, pneumonia e outras doenças respiratórias, bem como a exposição a resíduos químicos e tóxicos, matam milhões de moradores de favelas urbanas a cada ano." In: RIFKIN, Jeremy, La Civilización Empática La carrera hacia una conciencia global en un mundo en crisis. Madrid: Paidós, p. 416. Tradução livre da autora.
} 
objetivos só poderão ser atendidos caso o combate à corrupção for efetivado de uma forma a que não se lastime casos de impunidade.

Deveria ter sido incluído entre os Objetivos do Desenvolvimento Sustentável o combate à corrupção. Muitos programas financiados por organismos internacionais, pela iniciativa privada e por governos locais para a tutela do meio ambiente e para a melhoria do desenvolvimento humano da população mais carente têm recursos desviados pela corrupção nos países em desenvolvimento, impedindo a promoção efetiva de políticas sustentáveis. No mesmo sentido, a garantia do acesso à justiça para a promoção do desenvolvimento sustentável deveria ter sido incluída entre os objetivos, uma vez que as políticas públicas nos países em desenvolvimento frequentemente não funcionam a contento e a população necessita da intervenção do Poder Judiciário para a tutela de direitos fundamentais, como à saúde e à educação, e do meio ambiente equilibrado. (WEDY, 2017)

Um caso desastroso, de tragédia ambiental foi o ocorrido em Minas Gerais, onde o favorecimento nos licenciamentos das mineradoras levou aos desastres criminosos ocorridos nos municípios de Mariana e Brumadinho. Ações e omissões que agridem o meio ambiente, os direitos sociais e o princípio da sustentabilidade em todas suas dimensões.

Quanto à importância de considerar-se seriamente os riscos quando se envolvem empreendimentos ambientais, traz-se a título de argumentação o fato da tragédia ocorrida em Mariana/MG no ano de 2015 que teria sido evitada se as autoridades não menosprezassem os riscos do rompimento da barragem na empresa Samarco na época dos fatos. Veja-se trechos do livro da jornalista Cristina Serra sobre o assunto:

(.....) como é possível que tal sucessão de falhas tenha passado pelas instâncias de
decisão de uma empresa tão destacada no mercado e dirigida por executivos
premiados? (.....) Não foi, portanto, por falta da análise do risco que medidas
deixaram de ser tomadas. Os técnicos encaminharam suas avaliações às instâncias
superiores, que, segundo a investigação, deixaram de tomar as providências (....)
Ainda com relação à governança, registre-se que o painel de especialistas já
mencionado, o ITRB, contratado para vistoriar periodicamente as estruturas da
Samarco e dar orientações, fez alertas relevantes. Um relatório de outubro de 2011 ,
por exemplo, entre outras preocupações, destaca que as barragens da mineradora
eram estruturas extremamente perigosas, as mais altas barragens de rejeitos do
Brasil, possuindo um número elevado de defeitos e fraco desempenho, questões que
exigem alto nível de expertise técnica e experiência (...) (2018, p. 179/183)

Na mesma obra, o engenheiro geotécnico Jean Pierre Rémy, professor da UFRJ, quanto a terem a consciência do risco, e risco que não pode ser eliminado e que demanda uma ação proativa para impedir empreendimentos que podem gerar danos humanos e materiais (como também com os meninos da categoria de base do Flamengo - tragédia urbanística -, outro fato a ser considerado quando se trata do excesso de confiança no impedimento dos 
riscos), confirma que os profissionais são contratados com a pressão da emissão de laudos de acordo com os interesses dos empreendimentos (SERRA, 2018).

O meio ambiente, como bem de uso comum do povo, tutelado pelo artigo 225 da Constituição Federal de 1988, tem o espírito de proteção de qualidade de vida e de saúde, por isso, a determinação de dever constitucional de proteção pela coletividade e pelo poder público. Nesse sentido, todas as ações tendentes ao deferimento de licenças, praticadas nos procedimentos que gerem impactos ambientais, devem ser manejadas e seguidas a garantir a maior lisura e transparência e de maneira alguma se admite a existência de favores ou omissão com vistas a obter um aval do agente público. A determinação do $\S 1^{\circ}$, IV, do artigo mencionado, de forma expressa, exige a apresentação de estudo prévio de impacto ambiental com a mais ampla publicidade. Além de uma previsão de natureza preventiva e preservacionista, essa determinação já antevê a obrigação de reparação de qualquer dano ambiental. É uma assunção de consciência ambiental preservacionista e de obrigação coletiva, que por certo, inclui a observância da moralidade e exclui qualquer possibilidade de ato de corrupção.

Esse pensamento, é muito bem exposto por José Afonso da Silva (2005, p. 847):

\begin{abstract}
As normas constitucionais assumiram a consciência de que o direito à vida, como matriz de todos os direitos fundamentais do homem, é que há de orientar todas as formas de atuação no campo da tutela do meio ambiente. Compreendeu que ele é um valor preponderante, que há de estar acima de quaisquer considerações como a de desenvolvimento, como as de respeito ao direito de propriedade, como as da iniciativa privada. Todos esses são garantidos no texto constitucional, mas, a toda a evidência, não podem primar sobre o direito fundamental à vida, que está em jogo quando se discute a tutela da qualidade do meio ambiente, que é instrumental no sentido de que, através dessa tutela, o que se protege é um valor maior: a qualidade da vida humana.
\end{abstract}

Ocorre que desde a metáfora da "Tragédia dos Comuns", de Garret Hardin" (GARCIA, GUASQUE, 2018), já se vislumbrava a valoração econômica e ganhos pela utilização de recursos ambientais finitos, o meio ambiente analisado sob um viés econômico, como forma de obtenção de lucros, que sem qualquer limitação do Poder Público, está fadado ao desastre ambiental.

A obtenção desenfreada de lucros a partir de uso dos bens ambientais, com a preponderância do interesse econômico, poderá levar a sociedade ao esgotamento desses recursos, o que redundará em emergências globais, já que os danos ambientais não possuem fronteiras. A preponderância de um sistema capitalista de desenvolvimento insustentável, 
onde a corrupção não for atacada, cada vez mais será causa da poluição do ar e das águas, do desmatamento, da perda de espécies, atingindo a vida de todos no planeta (PIFFER, CANESTRINI, 2021).

Norteado no embasamento constitucional é que o licenciamento, de todos os modos, deve expressar o poder de polícia do Estado, fundado nas regras de integridade, em conformidade com os princípios ambientais e urbanísticos, limitando o poder econômico. Em um conceito compacto e bem delimitado:

O licenciamento ambiental expressa o poder de polícia inerente ao Estado e calca-se nos seguintes princípios ambientais: prevenção (previne os danos cuja certeza cientifica existem), precaução (evita eventuais danos de certeza científica incerta), poluidor-pagador (os custos do licenciamento correm às expensas do interessado), informação (há publicidade no licenciamento, inclusive com a possibilidade da realização de audiências públicas) e desenvolvimento sustentável (o licenciamento visa ao equilíbrio entre o meio ambiente e o desenvolvimento econômico). (ABIEÇAB, KURKOWSKI, p. 57)

A ganância humana só cresceu sem se preocupar com a ética e a sustentabilidade na governança ambiental, como bem retrata Bauman, quando trata da sociedade de consumo numa visão de sociedade dividida em guetos que sofrem a ausência de direitos sociais e são atingidos pela degradação ambiental, que vivem à margem de uma elite cercada em suas propriedades privadas e que podem pagar para obterem a satisfação de todos os seus desejos (BAUMAN, 1999).

No setor urbanístico, a valorização do solo e as diversas transações imobiliárias tornam esse setor grande fonte de poder econômico, podendo nessas relações, o poder público interferir a até favorecer certos atores envolvidos (o interesse inerente ao ato de corrupção) (SINGER, 1982).

Nesse setor, segundo Chiodelli e Moroni (2015), a corrupção ocorre por três formas: a regulatória ou legislativa (a atuação dos legisladores manipuladas por atos de corrupção para garantia de interesses privados); a burocrática (decorrente das diversas exigências normativas do ente público, favorecendo a autuação do funcionário público no desvio da conduta para o deferimento das licenças: a máxima de se impor dificuldades a fim de se vender facilidades); e a decorrente de fraudes diretas em obras públicas.

A responsabilidade corporativa dos empreendedores, por vezes, desconsidera as normas ambientais e urbanísticas em seus procedimentos de licenciamento, em razão de obtenção de lucros, conformando-se com atos de corrupção. 
Decorrente desse cenário, os licenciamentos passaram a ser alvo de corrupção, de uma forma devastadora, como já supramencionado, exigindo de forma premente o resgate de uma postura ética por parte do setor privado e do setor público, para combate a essa prática.

\section{Considerações Finais}

Analisou-se a existência dos atos de corrupção durante a história, de forma panorâmica e em um contexto filosófico, incluindo-se a análise dos casos no Brasil.

Da análise do exposto, nos conceitos de corrupção e como seu significado modificou por meio das diversas correntes de pensamentos ao longo da história, a identificação na cultura brasileira e a sua constatação de interferência nos empreendimentos urbanísticos e ambientais, tem-se que o objetivo do presente artigo foi alcançado, ou seja, a corrupção é um mal, decorrente da conduta do homem, que não consegue ser ao mesmo tempo adequada à moralidade e à legalidade e que traz vários prejuízos ao direito ambiental, urbanístico e aos direitos sociais dele decorrentes.

As práticas de sustentabilidade perpassam pela assunção de compromissos de integridade que sejam capazes de evitar atos de corrupção. A sustentabilidade somente poderá ser identificada quando as práticas ambientais, sociais e econômicas estiverem livres de atos de corrupção.

E essa realidade ideal somente poderá ser alcançada com a conscientização ambiental na sociedade, tanto por parte de seus agentes públicos como da sociedade em geral, para que as práticas de moralidade sejam vistas como necessárias a garantia do direito de todos, para a efetivação do que é bem público.

\section{Referências das Fontes Citadas}

ABI-EÇAB, Pedro; KURKOWSKI, Rafael Schwez. Resumo de Direito Ambiental. São Paulo: JHMizuno, 2020.

BARRETTO, Vicente de Paulo (coord.). Dicionário de Filosofia do Direito. Ed. Unisinos; Renovar. São Leopoldo/RS, Rio de Janeiro/RJ. 2009.

BAUMAN, Zygmunt. Globalização: as consequências humanas. Tradução de Marcus Penchel. Rio de Janeiro: Zahar, 1999. 
BOFF, Leonardo. Corrupção: crime contra a sociedade. (15 de abril de 2012). Disponível em: <http://www.ihu.unisinos.br/172-noticias/noticias-2012/508498-corrupcaocrimecontraaso ciedade>. Acesso em: 02 de ago. 2020.

BRASIL. Constituição da República Federativa do Brasil de 1988. Texto consolidado até a EC n. 91, de 2016. Portal da Presidência da República: Constituição. Brasília, DF. Disponível em: <http://www.planalto.gov.br/ccivil_03/constituicao/constituicaocompilado.htm">. Acesso em: 12 set. 2020.

CADORE, Tiago. Combate à corrupção para a Sustentabilidade. Rio de Janeiro: Lumen Juris. 2020.

CHIODELLI, Francesco; MORONI, Stefano. Corruption in land-use issues: a crucial challenge for planning theory and practice. The Town Planning Review, 86(4), 437-455. Disponível em http://dx.doi.org/10.3828/tpr.2015.27. Acesso em 28 de mar. 2021.

CORDEIRO, Carla Priscilla Barbosa Santos. A Corrupção sob um Prisma HistóricoSociológico: Análise de suas Principais Causas e Efeitos. In: Revista Eletrônica Direito e Conhecimento, n. 2, v. 1, 2017, Jul./Dez./2017, Arapiraca/AL. Disponível em: $<$ https://revistas.cesmac.edu.b r/index.php/dec/art icle/view/670>. Acesso em: 08 de ago. 2020.

DALlAGNOL Deltan. A Luta Contra a Corrupção - A lava jato e o futuro de um país marcado pela impunidade. Rio de Janeiro: Primeira Pessoa. 2017.

Dicionário de Filosofia. Disponível em https://sites.google.com/view/sbgdiciona riodefilosofia/corrup\%C3\%A7\%C3\%A3o Acesso em: 02 de ago. 2020.

FILGUEIRAS, Fernando. A tolerância à corrupção no Brasil: uma antinomia entre normas morais e prática social. Opin. Publica, Campinas, v. 15, n. 2, p. 386-421, nov. 2009.

Disponível em: <http://www.scielo.br/scielo.php?s cript=sci_arttext\&pid=S010462762009000200005\&lng=en\&nrm=iso>. Acesso em: 05 set. 2020.

FILGUEIRAS, Fernando. Sociedade civil e controle social da corrupção. Em Debate: Periódico de Opinião Pública e Conjuntura Política, Belo Horizonte, ano 3, n. 4, p. 14-28, dez. 2011. Disponível em: < http://bibliotecadi gital.tse. jus.br/xmlui/handle/bdtse/6094>. Acesso em: 05 de set. 2020.

GARCIA, Heloise Siqueira; GUASQUE, Bárbara. A análise econômica do Direito Ambiental a partir da visão da Dimensão Econômica da Sustentabilidade In: GUASQUE, Adriana; GUASQUE, Bárbara; GARCIA, Heloise Siqueira. Temas relevantes e atuais de direito e sustentabilidade ambiental. 1 ed.Alicante - Espanha: Instituto das Águas e Meio Ambiente na Universidade de Alicante, 2018, v.1, p. 89-114. https://rua.ua.es/ds pace/bitstream/10 045/83014/1/2018_Temasrelevantes-atuais-direito-sustentabilidade-ambiental.pdf

GIDDENS, Anthony. As Consequências da Modernidade. São Paulo: Ed. UNESP, 1991. 
GOMES, Laurentino. 1808 - Como uma rainha louca, um príncipe medroso e uma corte corrupta enganaram Napoleão e mudaram a História de Portugal e do Brasil. São Paulo: Globo. 2014, p. 178-179.

Grande Dicionário Houaiss. Corrupção. Disponível em < https://houaiss.uol.com.br/corpora tivo/apps/uol_www/v5-4/html/index.php\#1> Acesso em 27 de mar. 2021.

MACHIAVELLI, Niccolò. Comentários sobre a primeira década de Tito Lívio. Tradução: Sérgio Bath. Brasília: UNB, 1994.

Nações Unidas Brasil. Disponível em: <https://nacoe sunidas.org/pos2015/age nda2030/\#: :text=N\%C3\%B3s\%20resolvemos\%2C\%20entre\%20agora\%20e,

meninas\%3B\%20e\%20assegurar\%20a\%20prote\%C3\%A7\%C3\%A3o Acesso em: 06 de set de 2020.

NASCIMENTO, Mellilo Diniz do. O controle da corrupção no Brasil e a Lei no 12.846/2013 - Lei Anticorrupção. In: R. bras. de Dir. mun. - RBDM | Belo Horizonte, ano 17, n. 60, p. 79-137, abr./jun. 2016. Disponível em < https://ww w.editoraforum.com.br/wpcontent/uploads/2017/11/artigo-controle-corrup cao.pdf> Acesso em: 05 de set. 2020.

Organization for Economic Co-operation and Development. CleanGovBiz: Integrity in Practice. Paris, France, 2014. Disponível em: <https://pdfslide.net/g overnmentnonprofit/cleangovbiz-integrity-in-practice.html.> Acesso em 06 de set. 2020.

PASOLD, Cesar Luiz. Metodologia da Pesquisa Jurídica: teoria e prática. Florianópolis: Conceito Editorial, 2011.

PIFFER, Carla; ALVES, Jaime Leônidas Miranda; CANESTRINI, Valéria Giumelli. Políticas Públicas de Fraternidade e Solidariedade na Consolidação de um Estado de Direito Ecológico. In: CALGARO, Cleide (Org). Constitucionalismo e Meio Ambiente. Tomo IV: Diretrizes de Políticas Públicas Socioambientais. Porto Alegre: Editora Fi, 2021, p. 99-117.

PLATÃO A, O Estadista. Disponível em < http://www.gutenberg.org/files/1738/1738h/1738-h.htm> Acesso em 27 de mar. 2021.

PLATÃO B, Diálogos. Disponível em http://www.gutenberg.org/browse/authors/p\#a93 Acesso em 27 de mar. 2021.

POPPER, Karl R. A sociedade aberta e seus inimigos. Tradução: Milton Amado. Belo Horizonte: Itatiaia; São Paulo: Universidade de São Paulo, 1994.

PRESTES, Vanêsca Buzelato. Corrupção Urbanística: Da Ausência de Diferenciação entre Direito e Política no Brasil. Belo Horizonte: Fórum, 2018.

RIFKIN, Jeremy, La Civilización Empática - La carrera hacia una conciencia global en un mundo en crisis. Madrid: Paidós. 2010. 
ROMEIRO, Adriana. A corrupção na Época Moderna - conceitos e desafios metodológicos. Tempo, Niterói, v. 21, n. 38, pág. 216-237, dezembro de 2015. Disponível em: $\quad<h t t p: / / w w w . s c i e l o . b r / s c i e l o . p h p ? s c r i p t=s c i \_a r t t e x t \& p i d=S 1413-$ 77042015000200216\&ln g=en\&nrm=iso>. Acesso em: 05 de set. 2020.

SANTOS, Rafael Padilha dos. A moral e a justiça em Immanuel Kant [dissertação] / Rafael Padilha dos Santos; orientadora, Maria de Lourdes Alves Borges. - Florianópolis, SC, 2011. $230 \mathrm{p}$.

SERRA, Cristina. Tragédia em Mariana. Ed. Record, 2018.

SILVA, José Afonso da. Curso de Direito Constitucional Positivo. 25 ed. São Paulo: Malheiros, 2005.

SINGER, Paul. Uso do solo urbano na economia capitalista. In E. Maricato (Ed.), A produção capitalista da casa (e da cidade) no Brasil industrial. São Paulo: Alfa-Omega, 1982.

TANZI, V. Corruption Around the World: Causes, Consequences, Scope, and Cures. IMF Staff Papers, vol. 45, 1998.

Transparência Internacional Brasil. Disponível em: <http://www.transparenc iainternacional.org.br>. Acesso em: 06 de set. 2020.

WEDY, Gabriel. Marcos Recentes do Desenvolvimento Sustentável. In: RODRIGUES, Nina Tricia Disconzi; SPAREMBERGER, Raquel Fabiana Lopes; CALGARO, Cleide (Orgs.). Direito constitucional ecológico. [recurso eletrônico] / Nina Tricia Disconzi Rodrigues; Raquel Fabiana Lopes Sparemberger; Cleide Calgaro (Orgs.) -- Porto Alegre, RS: Editora Fi, 2017. 